Cite this: J. Mater. Chem. C, 2014, 2, 1791

Received 21st October 2013

Accepted 20th December 2013

DOI: $10.1039 / c 3 t c 32086 c$

www.rsc.org/MaterialsC

\section{Platinum(II) complexes with cyclometallated 5- $\pi$-delocalized-donor-1,3-di(2-pyridyl)benzene ligands as efficient phosphors for NIR-OLEDs $\uparrow$}

\author{
Filippo Nisic, ${ }^{a}$ Alessia Colombo, ${ }^{a}$ Claudia Dragonetti, ${ }^{a b}$ Dominique Roberto, ${ }^{* a b}$

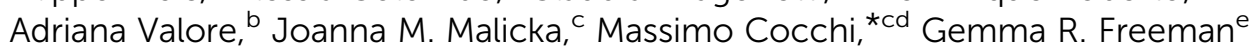 \\ and J. A. Gareth Williams*e
}

Two new pincer proligands, namely 5-(p-(N,N-diphenylamino)phenylethynyl)-1,3-di(2-pyridyl)benzene $\left(\mathrm{HL}^{1}\right)$ and trans-5-( $p$ - $\left(\mathrm{N}, \mathrm{N}\right.$-diphenylamino)styryl-1,3-di(2-pyridyl)benzene $\left(\mathrm{HL}^{2}\right)$ were prepared together with their $\mathrm{N}^{\wedge} \mathrm{C}^{\wedge} \mathrm{N}$-coordinated cyclometallated platinum(II) complexes $\mathrm{PtL}^{1} \mathrm{X}(\mathrm{X}=\mathrm{Cl}, \mathrm{NCS})$ and $\mathrm{PtL}^{2} \mathrm{Cl}$. Both ligands are intensely luminescent in solution (quantum yields $>0.8$ ). $\mathrm{PtL}^{1} \mathrm{X}$ complexes display high quantum yields in solution whereas that of $\mathrm{PtL}^{2} \mathrm{Cl}$ is very low due to the ease with which trans to cis isomerisation of the diphenylaminostyryl $\mathrm{C}=\mathrm{C}$ bond occurs. Distinct sets of emission bands attributable to the cis and trans forms are observable in glass at $77 \mathrm{~K}$, the assignments being supported by TD-DFT calculations. Organic light-emitting diodes (OLEDs) have been prepared using the new compounds as phosphorescent emitters. Remarkably, despite the inferior quantum yield of $\mathrm{PtL}^{2} \mathrm{Cl}$ in solution, the best electroluminescence quantum efficiencies are obtained with this complex, which emerges as an excellent candidate for the preparation of NIR-OLEDs.

\section{Introduction}

There has been a growing interest in the design of luminescent transition metal complexes as phosphors for organic lightemitting devices (OLEDs) over the past decade. ${ }^{1-3}$ In OLEDs, light emission arises from the radiative deactivation of electronic excited states that are formed by recombination of charge carriers - i.e. electrons and holes - injected from the electrodes. Because phosphorescent emitters doped into fluorescent host materials can potentially harvest both singlet and triplet excitons upon electron-hole recombination, their use in place of fluorescent compounds may potentially improve the luminous efficiency. Complexes of third-row transition metal ions are particularly suitable for this purpose, since the high spin-orbit coupling constant and high intersystem crossing associated with them efficiently promote emission from the otherwise

\footnotetext{
aDipartimento di Chimica dell'Università degli Studi di Milano, UdR INSTM di Milano, via Golgi 19, 20133 Milano, Italy

${ }^{b}$ ISTM-CNR, Via Golgi 19, 20133 Milano, Italy.E-mail: dominique.roberto@unimi.it 'Consorzio MIST E-R scrl, Via P. Gobetti 101, 40129 Bologna, Italy

${ }^{d}$ Istituto per la Sintesi Organica e la Fotoreattività (ISOF), Consiglio Nazionale delle Ricerche (CNR), Via P. Gobetti 101, 40129 Bologna, Italy. E-mail: cocchi@isof.cnr.it ${ }^{e}$ Department of Chemistry, University of Durham, South Road, Durham, DH1 3LE, UK. E-mail: j.a.g.williams@durham.ac.uk

$\dagger$ Electronic supplementary information (ESI) available: NMR data for trans-cis isomerisation of $\mathbf{P t L}^{2} \mathbf{C l}$ in solution; absorption and emission spectra of $\mathbf{P t L}^{1} \mathbf{N C S}$; simulated absorption spectra of cis and trans $\mathbf{P t L}^{2} \mathbf{C l}$ obtained by TD-DFT calculations and additional OLED data. See DOI: 10.1039/c3tc32086c
}

wasted triplet states, which represent up to $75 \%$ of the excited states formed upon charge-recombination in an electroluminescent device. ${ }^{1-3}$

Though the field has to date been dominated by complexes of iridium(III), which are already used in many devices, platinum(II) complexes attract increasing interest. Part of the motivation for turning to platinum(II) lies in the propensity of square-planar $\mathrm{d}^{8}$ complexes to undergo face-to-face bimolecular interactions, which may lead to excimeric or aggregate emissions that are not normally possible in $\mathrm{d}^{6}$ complexes. ${ }^{4}$ Several families of $\mathrm{Pt}(\mathrm{II})$ complexes have been discovered that are brightly luminescent in solution at room temperature., ${ }^{4,5} \mathrm{~A}$ convenient strategy to improve luminescence is to make use of cyclometallating ligands, whose strong ligand fields tend to favour emission efficiencies, as they raise the energies of otherwise deactivating metal-centred states, making them thermally inaccessible and thus reducing non-radiative decay pathways. Meanwhile, tridentate ligands have been found to offer an advantage over bidentate ligands in that they impart higher rigidity on the complex, inhibiting distortion and reducing non-radiative decay. ${ }^{6,7}$

$\mathrm{Pt}(\mathrm{II})$ complexes with tridentate ligands based on cyclometallated 1,3-di(2-pyridyl)benzene (dpyb), ${ }^{8}$ which offer the metal ion an $\mathrm{N}^{\wedge} \mathrm{C}^{\wedge} \mathrm{N}$ coordination environment, are amongst the brightest Pt-based emitters in solution at room temperature. ${ }^{9}$ This structural motif has also been found to lead to significant second-order nonlinear optical properties. ${ }^{10}$ Remarkably, the emission color of OLEDs based on these 
complexes can be easily tuned, for example, from blue to red by increasing the donor ability of the substituent at the central 5-position of the cyclometallating ring. ${ }^{11}$

On the other hand, OLEDs that emit in the near-infrared (NIR) region represent an intrinsically challenging target, owing to the tendency of non-radiative decay processes to increase as the excited-state energy decreases ${ }^{\mathbf{1 2}}$ and, simultaneously, of the radiative decay constants to decrease. Two classes of NIRemitting OLEDs based on metal complexes are known. The first utilizes lanthanide cations as the emitting centres with emission around $1000 \mathrm{~nm}$ but with a very low external electroluminescence quantum efficiency (EL QE). ${ }^{13}$ The second class uses dblock metal complexes with highly conjugated ligands, characterized by higher EL QE but much shorter $\lambda_{\max }$ values. For example, efficient phosphorescent NIR-OLEDs based on Ptporphyrins have been reported recently, with emission maxima at around $770 \mathrm{~nm} .{ }^{\mathbf{1 4}}$ The challenge is now to shift the $\lambda_{\max }$ of transition metal-based OLEDs to lower energy, whilst maintaining a high EL QE efficiency.

One way to tune emission towards the red and NIR is to make use of bimolecular excited states; for example, excimer or aggregate states of square-planar Pt(II) complexes that undergo energy-minimising face-to-face interactions. ${ }^{4 m, 15}$ Recently some of us found that the complex PtL ${ }^{\text {mes }} \mathrm{NCS}\left\{\mathrm{L}^{\text {mes }}=5\right.$-mesityl-1,3-di(2pyridyl)-benzene $\}$ allows the preparation of OLEDs that emit squarely in the NIR region $\left(\lambda_{\max }=855 \mathrm{~nm}\right)$, through the formation of such aggregate species and their efficient emission. ${ }^{\mathbf{1 6}}$

In this paper, we describe the effect of the incorporation of $\pi$-delocalized $\mathrm{ArC}=\mathrm{C}$ - and $\mathrm{ArC} \equiv \mathrm{C}$ - substituents at the central 5 -position of the phenyl ring of dpyb. The absorption, photoluminescence, and electroluminescence properties of the $\mathrm{N}^{\wedge} \mathrm{C}^{\wedge} \mathrm{N}$-cyclometallated $\mathrm{Pt}(\mathrm{II})$ complexes are investigated, and we show how one of these novel compounds is a good candidate for the preparation of efficient NIR OLEDs.

\section{Experimental}

\section{General comments}

Solvents were dried by standard procedures: THF was freshly distilled from $\mathrm{Na} /$ benzophenone under a nitrogen atmosphere, $N, N$-dimethylformamide (DMF) was dried over activated molecular sieves and triethylamine $\left(\mathrm{Et}_{3} \mathrm{~N}\right)$ was freshly distilled over $\mathrm{KOH}$. All reagents were purchased from Sigma-Aldrich and were used without further purification. Reactions requiring anhydrous or oxygen-free conditions were performed under nitrogen. Thin layer chromatography (TLC) was carried out with pre-coated Merck F254 silica gel plates. Flash chromatography (FC) was carried out with Macherey-Nagel silica gel 60 (230-400 mesh).

${ }^{1} \mathrm{H}$ and ${ }^{13} \mathrm{C}$ spectra were recorded at $400 \mathrm{MHz}$ on a Bruker AVANCE-400 instrument. Chemical shifts $(\delta)$ for ${ }^{1} \mathrm{H}$ and ${ }^{13} \mathrm{C}$ spectra are expressed in ppm relative to internal $\mathrm{Me}_{4} \mathrm{Si}$ as standard. Signals are abbreviated as s, singlet; bs, broad singlet; $\mathrm{d}$, doublet; t, triplet; q, quartet; m, multiplet. Mass spectra were obtained with a FT-ICR Mass Spectrometer APEX II \& Xmass software (Bruker Daltonics) - 4.7 Magnet and Autospec Fission Spectrometer (FAB ionization). Elemental analyses were performed using an Exeter Analytical E-440 analyser.

\section{Synthesis of new ligands and complexes}

Synthesis of $5-(p-(N, N$-diphenylamino $)$ phenylethynyl $)-1,3-$ di(2-pyridyl)benzene $\left(\mathrm{HL}^{1}\right)$ and trans-5- $(p-(N, N$-diphenylamino $)$ styryl)-1,3-di(2-pyridyl)benzene ( $\left.\mathbf{H L}^{2}\right)$. The new ligands $\mathbf{H L}^{\mathbf{1}}$ and $\mathbf{H L}^{2}$ were prepared as shown in Scheme 1 from 5 -substituted $m$-dibromobenzene derivatives ( $\mathbf{1}$ and 2 ) synthesized as follows.

Synthesis of 4-((3,5-dibromophenyl)ethynyl)- $N, N$-diphenylaniline (1). To a solution of 4-ethynyl- $N, N$-diphenylaniline (196 mg, 1 equiv.) and 1,3,5-tribromobenzene (253 mg, 1.1 equiv.) in degassed triethylamine $(7.5 \mathrm{~mL})$ were added $\mathrm{PdCl}_{2}\left(\mathrm{PPh}_{3}\right)_{2}(30.7 \mathrm{mg})$, CuI (3.8 mg) and $\mathrm{PPh}_{3}(5.2 \mathrm{mg})$ under a flow of nitrogen gas. The reaction mixture was stirred at $70{ }^{\circ} \mathrm{C}$ for $18 \mathrm{~h}$. The solvent was removed under reduced pressure and the residue was purified by flash chromatography, using hexane-dichloromethane $9: 1$ as an eluent, to give a pale yellow solid (220 mg; 60\%). ${ }^{1} \mathrm{H}-\mathrm{NMR}\left(400 \mathrm{MHz} \mathrm{CDCl}_{3}\right.$ ): $\delta 7.59(1 \mathrm{H}, \mathrm{t}, J$ $=1.6 \mathrm{~Hz}), 7.57(2 \mathrm{H}, \mathrm{d}, J=1.6 \mathrm{~Hz}), 7.33(2 \mathrm{H}, \mathrm{d}, J=8.8 \mathrm{~Hz}), 7.29$ $(4 \mathrm{H}, \mathrm{t}, J=7.2 \mathrm{~Hz}, J=8.4 \mathrm{~Hz}), 7.12(4 \mathrm{H}, \mathrm{d}, J=8.4 \mathrm{~Hz}), 7.08(2 \mathrm{H}, \mathrm{t}$, $J=7.2 \mathrm{~Hz}, J=8.4 \mathrm{~Hz}), 6.98(2 \mathrm{H}, \mathrm{d}, J=8.8 \mathrm{~Hz}) .{ }^{13} \mathrm{C}-\mathrm{NMR}(100$ $\left.\mathrm{MHz}, \mathrm{CDCl}_{3}\right): \delta 148.7,147.1,133.6,132.9,132.8,129.6,127.3$, 125.4, 123.9, 122.7, 121.9, 114.8, 92.6, 85.8.

Synthesis of $(E)-4-(3,5-d i b r o m o s t y r y l)-N, N$-diphenyl-aniline (2). This new compound was prepared following a slightly modified reported synthetic procedure. ${ }^{17}$ To a solution of 1,3dibromo-5-diethoxy-phosphorylmethylbenzene (380 mg, 1.1 equiv.) and 4-(diphenylamino)benzaldehyde (305 mg, 1 equiv.) in THF ( $9 \mathrm{~mL}$ ) cooled to $0{ }^{\circ} \mathrm{C}$ under a nitrogen atmosphere was added, in small portions, potassium tert-butoxide (323 mg, 2.6 equiv.). The cool bath was then removed and the mixture stirred at room temperature for $18 \mathrm{~h}$. After hydrolysis with water, the mixture was stirred for a further $30 \mathrm{~min}$, diluted with AcOEt and washed with water. The organic layer was dried over anhydrous $\mathrm{Na}_{2} \mathrm{SO}_{4}$ and concentrated. The crude product obtained was

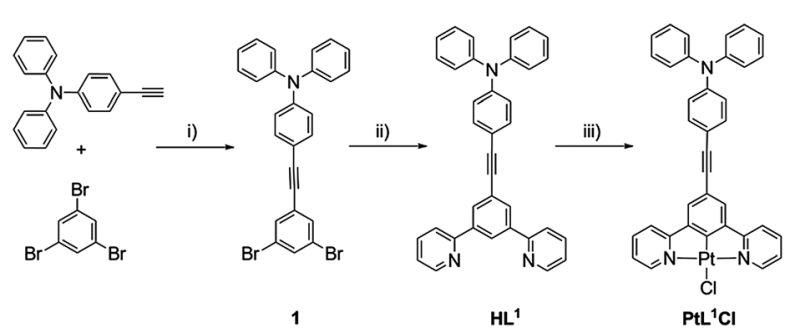

i) $\mathrm{Pd}\left(\mathrm{PPh}_{3}\right)_{2} \mathrm{Cl}_{2}, \mathrm{Cul}, \mathrm{PPh}_{3}, \mathrm{TEA}, 70^{\circ} \mathrm{C}, 16 \mathrm{~h}, 60 \%$; ii) 2-(tri-n-butylstannyl)pyridine, $\mathrm{Pd}\left(\mathrm{PPh}_{3}\right)_{2} \mathrm{Cl}_{2}, \mathrm{CuO}$ DMF, MW $160^{\circ} \mathrm{C}, 45^{\prime}, 62 \%$; iii) $\mathrm{K}_{2} \mathrm{PtCl}_{4}, \mathrm{AcOH} / \mathrm{H}_{2} \mathrm{O} 9: 1, \mathrm{MW} 160^{\circ} \mathrm{C}, 45^{\prime}, 50 \%$.

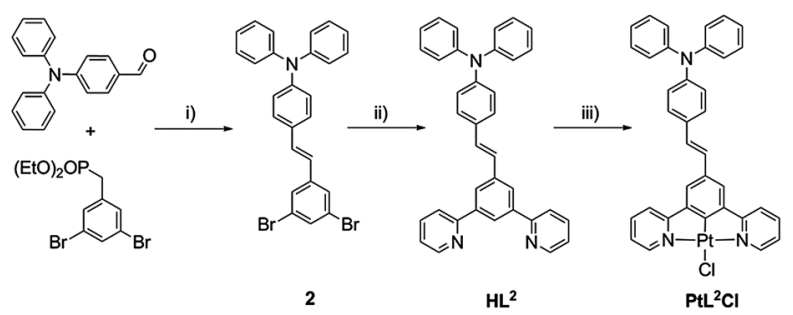

i) tBuO' $\mathrm{K}^{+}, \mathrm{THF}, \mathrm{RT}, 16 \mathrm{~h}, 80 \%$; ii) 2-(tri-n-butylstannyl)pyridine, $\mathrm{Pd}\left(\mathrm{PPh}_{3}\right)_{2} \mathrm{Cl}_{2}, \mathrm{CuO}, \mathrm{DMF}, \mathrm{MW} 160^{\circ} \mathrm{C}$ $45^{\prime}, 65 \%$; iii) $\mathrm{K}_{2} \mathrm{PtCl}_{4}, \mathrm{AcOH} / \mathrm{H}_{2} \mathrm{O} 9: 1, \mathrm{MW} 160^{\circ} \mathrm{C}, 45^{\prime}, 55 \%$.

Scheme 1 Synthesis of the new compounds $\mathrm{HL}^{1}, \mathrm{HL}^{2}, \mathrm{PtL}^{1} \mathrm{Cl}$ and $\mathrm{PtL}^{2} \mathrm{Cl}$. 
purified by flash chromatography, using hexane-dichloromethane $8: 2$ as the eluent, to give the product as a pale yellow solid (444 mg; 80\%). ${ }^{1} \mathrm{H}-\mathrm{NMR}\left(400 \mathrm{MHz}, \mathrm{CDCl}_{3}\right): \delta 7.56(2 \mathrm{H}, \mathrm{d}, J$ $=1.6 \mathrm{~Hz}), 7.52(1 \mathrm{H}, \mathrm{t}, J=1.6 \mathrm{~Hz}), 7.37(2 \mathrm{H}, \mathrm{d}, J=8.8 \mathrm{~Hz}), 7.32-$ $7.29(4 \mathrm{H}, \mathrm{m}), 7.14(4 \mathrm{H}, \mathrm{d}, J=7.6 \mathrm{~Hz}), 7.11-7.04(5 \mathrm{H}, \mathrm{m}), 6.83$ $\left(1 \mathrm{H}, \mathrm{d}, J_{\text {trans }}=16 \mathrm{~Hz}\right) \cdot{ }^{13} \mathrm{C}-\mathrm{NMR}\left(100 \mathrm{MHz}, \mathrm{CDCl}_{3}\right): \delta 148.3$, $147.4,141.5$, 132.3, 131.1, 130.1, 129.4, 127.9, 127.8, 127.6, 124.7, 123.7, 123.5, 123.3, 123.1 .

\section{General procedure for the synthesis of $\mathrm{HL}^{1}$ and $\mathrm{HL}^{2}$}

Under a nitrogen atmosphere, a mixture of the 5-substituted $m$-dibromobenzene derivative (1 equiv.), 2-(tri- $n$-butylstannyl) pyridine (3 equiv.), $\mathrm{PdCl}_{2}\left(\mathrm{PPh}_{3}\right)_{2}$ (0.1 equiv.), $\mathrm{CuO}$ (3 equiv.) and DMF $(0.1 \mathrm{M})$ was placed in a microwave reactor at $160{ }^{\circ} \mathrm{C}$ $(250 \mathrm{~W})$ for $45 \mathrm{~min}$, controlling the flow rate of cooling air. After cooling to room temperature, the reaction mixture was poured into ethyl acetate and filtered. The filtrate was washed with water and the organic layer was dried over anhydrous $\mathrm{Na}_{2} \mathrm{SO}_{4}$ and concentrated under reduced pressure. The crude product obtained was purified by flash chromatography, using hexaneethyl acetate $8: 2$ as the eluent.

Data for 5-( $p$-( $N, N$-diphenylamino)phenylethynyl)-1,3-di(2pyridyl)benzene $\left(\mathbf{H L}^{\mathbf{1}}\right)$. Yield $252 \mathrm{mg}, 62 \%$. ${ }^{1} \mathrm{H}-\mathrm{NMR}(400 \mathrm{MHz}$, $\left.\mathrm{CDCl}_{3}\right): \delta 8.73(2 \mathrm{H}, \mathrm{ddd}, J=4.8 \mathrm{~Hz}, J=1.6 \mathrm{~Hz}, J=0.8 \mathrm{~Hz}), 8.59$ $(1 \mathrm{H}, \mathrm{t}, J=1.6 \mathrm{~Hz}), 8.21(2 \mathrm{H}, \mathrm{d}, J=1.6 \mathrm{~Hz}), 7.87(2 \mathrm{H}, \mathrm{td}, J=0.8$ $\mathrm{Hz}, J=8 \mathrm{~Hz}, J=2 \mathrm{~Hz}), 7.79(2 \mathrm{H}, \mathrm{dt}, J=1.6 \mathrm{~Hz}, J=8 \mathrm{~Hz}, J=3.6$ $\mathrm{Hz}), 7.41(2 \mathrm{H}, \mathrm{d}, J=8.8 \mathrm{~Hz}), 7.31-7.26(6 \mathrm{H}, \mathrm{m}), 7.13(4 \mathrm{H}, \mathrm{dd}, J=$ $7.6 \mathrm{~Hz}, J=1.2 \mathrm{~Hz}), 7.07(4 \mathrm{H}, \mathrm{tt}, J=7.2 \mathrm{~Hz}, J=1.2 \mathrm{~Hz}), 7.01(2 \mathrm{H}$, $\mathrm{d}, J=8.8 \mathrm{~Hz}) \cdot{ }^{13} \mathrm{C}-\mathrm{NMR}\left(100 \mathrm{MHz}, \mathrm{CDCl}_{3}\right): \delta 156.6,149.7,148.1$, $147.3,140.2$, 136.9, 132.7, 130.4, 129.5, 125.2, 124.9, 123.7, 122.7, 122.4, 120.9, 116.1, 90.3, 88.6. $\mathrm{MS}\left(\mathrm{FAB}^{+}\right): \mathrm{m} / z$ 499. Anal. calcd (\%) for $\mathrm{C}_{36} \mathrm{H}_{25} \mathrm{~N}_{3}$ : C 86.55, H 5.04, N 8.41. Found: C 86.61, $\mathrm{H}$ 5.03, N 8.37\%.

Data for trans-5-( $p$-( $N, N$-diphenylamino)styryl)-1,3-di(2-pyridyl)benzene $\left(\mathrm{HL}^{2}\right)$. Yield $247 \mathrm{mg}, 65 \% .{ }^{1} \mathrm{H}-\mathrm{NMR}(400 \mathrm{MHz}$, $\left.\mathrm{CDCl}_{3}\right): \delta 8.76(2 \mathrm{H}, \mathrm{d}, J=4.8 \mathrm{~Hz}), 8.46(1 \mathrm{H}, \mathrm{s}), 8.23(2 \mathrm{H}, \mathrm{s}), 7.92$ $(2 \mathrm{H}, \mathrm{d}, J=7.6 \mathrm{~Hz}), 7.83(2 \mathrm{H}, \mathrm{dt}, J=7.6 \mathrm{~Hz}, J=2.4 \mathrm{~Hz}, J=3.6$ $\mathrm{Hz}), 7.43(2 \mathrm{H}, \mathrm{d}, J=8.4 \mathrm{~Hz}), 7.32-7.25(7 \mathrm{H}, \mathrm{m}), 7.19-7.11(5 \mathrm{H}$, $\mathrm{m}), 7.08-7.02(4 \mathrm{H}, \mathrm{m}) .{ }^{13} \mathrm{C}-\mathrm{NMR}\left(100 \mathrm{MHz}, \mathrm{CDCl}_{3}\right): \delta$ 156.9, $149.4,147.5,139.9,138.9,137.2$, 131.3, 129.3, 129.2, 127.5, 126.4, 125.6, 124.6, 124.4, 123.4, 123.1, 122.5, 121.1. $\mathrm{MS}\left(\mathrm{FAB}^{+}\right)$: $m / z$ 501. Anal. calcd (\%) for $\mathrm{C}_{36} \mathrm{H}_{27} \mathrm{~N}_{3}$ : C 86.20, H 5.43, N 8.38. Found: C 86.23, H 5.41, N 8.35\%.

\section{Procedure for the synthesis of $\mathrm{PtL}^{1} \mathrm{Cl}$ and $\mathrm{PtL}^{2} \mathrm{Cl}$ (ref. 18)}

Under a nitrogen atmosphere, a solution of $\mathrm{K}_{2} \mathrm{PtCl}_{4}$ (1 equiv.) and $\mathbf{H L}^{1}$ or $\mathbf{H L}^{2}$ (1 equiv.) in a $\mathrm{AcOH}-\mathrm{H}_{2} \mathrm{O} 9: 1$ mixture $(0.3 \mathrm{M})$ was placed in a microwave reactor at $160{ }^{\circ} \mathrm{C}(250 \mathrm{~W})$ for $45 \mathrm{~min}$ controlling the flow rate of cooling air. After cooling to room temperature, the reaction mixture was filtered. The precipitate was washed successively with methanol, water, ethanol and diethyl ether.

PtL ${ }^{1}$ Cl. Yield $87 \mathrm{mg}, 50 \% .{ }^{1} \mathrm{H}-\mathrm{NMR}\left(400 \mathrm{MHz}, \mathrm{CD}_{2} \mathrm{Cl}_{2}\right.$ ): $\delta 9.34$ $(2 \mathrm{H}, \mathrm{bs}), 8.04(2 \mathrm{H}, \mathrm{t}, J=7.6 \mathrm{~Hz}, J=8 \mathrm{~Hz}), 7.92(2 \mathrm{H}, \mathrm{d}, J=8.8 \mathrm{~Hz})$, $7.75(2 \mathrm{H}, \mathrm{d}, J=7.6 \mathrm{~Hz}), 7.44(2 \mathrm{H}, \mathrm{s}), 7.39-7.32$ (6H, m), 7.21-7.19 $(6 \mathrm{H}, \mathrm{m}), 7.01(2 \mathrm{H}, \mathrm{d}, J=8.8 \mathrm{~Hz}) . \mathrm{MS}\left(\mathrm{FAB}^{+}\right): m / z 693[\mathrm{M}-\mathrm{Cl}]$.
Anal. calcd (\%) for $\mathrm{C}_{36} \mathrm{H}_{24} \mathrm{ClN}_{3}$ Pt: C 59.30, H 3.32, N 5.76. Found: C 59.43, H 3.33, N 5.68\%.

PtL $^{2}$ Cl. Yield $82 \mathrm{mg}, 55 \% .{ }^{1} \mathrm{H}-\mathrm{NMR}\left(400 \mathrm{MHz}, \mathrm{CD}_{2} \mathrm{Cl}_{2}\right): \delta 9.31$ $(2 \mathrm{H}, \mathrm{bddd}, J=4.2 \mathrm{~Hz}, J=22 \mathrm{~Hz}), 8.03(2 \mathrm{H}, \mathrm{t}, J=7.6 \mathrm{~Hz}), 7.82$ $(2 \mathrm{H}, \mathrm{d}, J=7.6 \mathrm{~Hz}), 7.67$ (2H, s), 7.49 (2H, d, $J=8.8 \mathrm{~Hz}), 7.35-$ $7.31(6 \mathrm{H}, \mathrm{m}), 7.23\left(1 \mathrm{H}, \mathrm{d}, J_{\text {trans }}=16.4 \mathrm{~Hz}\right), 7.16-7.08(9 \mathrm{H}, \mathrm{m})$. HET-COR $\left({ }^{1} \mathrm{H}-{ }^{13} \mathrm{C}, \mathrm{CD}_{2} \mathrm{Cl}_{2}\right): \delta 152.6,139.9,129.9,127.7,125.1$, 124.1, 123.7, 122.6, 120.1. $\mathrm{MS}\left(\mathrm{FAB}^{+}\right): m / z 695[\mathrm{M}-\mathrm{Cl}]$. Anal. calcd (\%) for $\mathrm{C}_{36} \mathrm{H}_{26} \mathrm{ClN}_{3} \mathrm{Pt}$ : $\mathrm{C} 59.14, \mathrm{H} 3.58, \mathrm{~N}$ 5.75. Found: $\mathrm{C}$ 59.08, H 3.57, N 5.83\%.

\section{Synthesis of $\mathrm{PtL}^{1} \mathrm{NCS}$}

A solution of PtL $^{1} \mathbf{C l}$ (125 mg; 1 equiv.) in dichloromethane $(300 \mathrm{~mL})$ was treated with a solution of sodium thiocyanate $(15.1$ mg; 1.1 equiv.) in methanol $(2 \mathrm{~mL})$. After stirring at room temperature under nitrogen for $24 \mathrm{~h}$, the solution was filtered and the solvent evaporated to dryness affording the crude product that was washed first with methanol and then with ethanol.

Yield $90.1 \mathrm{mg} ; 70 \% .{ }^{1} \mathrm{H}$ NMR (400 MHz, $\left.\mathrm{CD}_{2} \mathrm{Cl}_{2}\right): \delta 8.60(\mathrm{~d}$, $2 \mathrm{H}, J=5.2 \mathrm{~Hz}), 7.99(\mathrm{~m}, 4 \mathrm{H}), 7.61(\mathrm{~d}, 2 \mathrm{H}, J=7.8 \mathrm{~Hz}), 7.38(\mathrm{~m}$, $10 \mathrm{H}), 7.21(\mathrm{~m}, 4 \mathrm{H}), 7.04$ (d, 2H, $J=7.8 \mathrm{~Hz})$.

$\mathrm{MS}\left(\mathrm{FAB}^{+}\right): m / z 753[\mathrm{M}]$. Anal. calcd (\%) for $\mathrm{C}_{37} \mathrm{H}_{26} \mathrm{~N}_{4} \mathrm{PtS}: \mathrm{C}$ 58.96, H 3.48, N 7.43. Found: C 58.89, H 3.46, N 7.51\%.

\section{Photophysical measurements}

Absorption spectra were recorded for solutions in dichloromethane within $1 \mathrm{~cm}$ pathlength quartz cuvettes using a Biotek Instruments XS spectrometer. Luminescence spectra were recorded using a FluoroMax-2 spectrofluorimeter equipped with an R928 photomultiplier tube. Spectra were corrected for the wavelength dependence of the detector and emission grating. Quantum yields were determined using appropriate standards. For the proligands, a solution of quinine sulfate in 1 $\mathrm{M} \mathrm{H}_{2} \mathrm{SO}_{4}$ (aq.) was used $(\Phi=0.548) .{ }^{19}$ For the $\mathrm{Pt}(\mathrm{II})$ complexes, $\left[\mathrm{Ru}(\text { bpy })_{3}\right] \mathrm{Cl}_{2}$ in $\mathrm{H}_{2} \mathrm{O}(\Phi=0.028)$ (ref. 20) was used as the standard, and values were cross-checked against $\mathrm{PtL}^{\mathrm{H}} \mathrm{Cl}\left\{\mathrm{L}^{\mathrm{H}}=\right.$ 1,3-di(2-pyridyl)-benzene $\}(\Phi=0.90) .{ }^{9 a}$ The luminescence lifetimes of the complexes were measured by time-correlated single-photon counting, following excitation with a pulsed laser diode at $374 \mathrm{~nm}$ or $405 \mathrm{~nm}$. The emitted light was detected at $90^{\circ}$ using a Peltier-cooled R928 photomultiplier tube after passage through a monochromator. ${ }^{21}$

\section{Density functional theory calculations}

Calculations were performed using the Gaussian 09 suite of programmes $^{22}$ with the PBE0 functional. ${ }^{23 a}$ The LANL2DZ basis set was used for Pt(II), with the inner core electrons replaced by a relativistic core potential, and the all-electron cc-PVDZ basis set was used for the ligands. A polarised continuum model (PCM) was used for the solvent dichloromethane. Geometries were fully optimised without symmetry constraints, and the triplet state geometries were calculated directly by minimisation of the SCF triplet state. Harmonic vibrational wavenumber calculations were performed to confirm that the structures obtained correspond to minima of the potential energy surface. Timedependent calculations were carried out on the optimised 
structures to determine the relevant transitions and for the generation of density difference plots. The spectral simulations were performed by convolution using a Gaussian-shape function of $0.6 \mathrm{eV}$ full-width at half-maximum, as described elsewhere, ${ }^{23 b}$ using the ten lowest-energy spin-allowed transitions.

\section{Procedure for OLED fabrication and assessment}

OLEDs were fabricated by growing a sequence of thin layers on clean glass substrates pre-coated with a layer of indium tin oxide (ITO), $120 \mathrm{~nm}$ thick, with a sheet resistance of $20 \Omega$ per square. A 2 nm-thick hole-injecting layer of $\mathrm{Mo}_{2} \mathrm{O}_{x}$ was deposited on top of the ITO by thermal evaporation under high vacuum of $\sim 10^{-6} \mathrm{hPa}$. All remaining organic layers were deposited in succession by thermal evaporation under high vacuum, followed by thermal evaporation of the cathode layer consisting of $0.5 \mathrm{~nm}$ thick LiF and a $100 \mathrm{~nm}$ thick aluminium cap. The emitting layer (EML) was evaporated by co-deposition of $\mathbf{P t L}^{2} \mathbf{C l}$ and $4,4^{\prime}, 4^{\prime \prime}$-tris $(N$-carbazolyl)triphenylamine (TCTA) or 4,4- $N, N^{\prime}$-dicarbazolyl-1, $1^{\prime}$-biphenyl (CBP) to form a 30 nm-thick blend film (5 wt\% Pt complex : $95 \mathrm{wt} \%$ TCTA or CBP), or by single deposition of the $\mathrm{Pt}(\mathrm{II})$ complex only, to form a $15 \mathrm{~nm}$ neat film. The current-voltage characteristics were measured with a Keithley Source-Measure unit, model 236, under continuous operation mode, while the light output power was measured with an EG\&G power meter, and electroluminescence (EL) spectra recorded with a StellarNet spectroradiometer. All measurements were carried out at room temperature under an argon atmosphere and were reproduced for many runs, excluding chemical reaction with oxygen or moisture. The performance of the emissive layer was optimized by locating the EML between exciton-blocking layers of TCTA (or CBP) $(80 \mathrm{~nm}$ thick) and 1,3,5-tris( $N$-phenylbenzimidazole-2-yl)benzene (TPBi) (25 $\mathrm{nm}$ thick), the latter acting also as an electron-transporting and hole-blocking layer.

\section{Results and discussion}

\section{Preparation of the new ligands and Pt(II) complexes}

The new proligands 5-( $p$-( $N, N$-diphenylamino)phenyl-ethynyl)1,3-di(2-pyridyl)benzene $\left(\mathbf{H L}^{\mathbf{1}}\right)$ and trans-5-( $p$-( $N, N$-diphenylamino)styryl)-1,3-di(2-pyridyl)benzene $\left(\mathbf{H L}^{2}\right)$ were synthesized from 5 -substituted $m$-dibromobenzene derivatives, as shown in Scheme 1.

Complexes $\mathbf{P t L}{ }^{1} \mathbf{C l}$ and $\mathbf{P t L}^{2} \mathbf{C l}$ were prepared by reaction of $\mathrm{K}_{2} \mathrm{PtCl}_{4}$ with $\mathbf{H L}^{1}$ and $\mathbf{H L}^{2}$ respectively, in a $\mathrm{AcOH}-\mathrm{H}_{2} \mathrm{O}(9: 1 \mathrm{v} / \mathrm{v})$ mixture placed in a microwave reactor at $160{ }^{\circ} \mathrm{C}$ for $45 \mathrm{~min}$, as previously described for other Pt(II) complexes. ${ }^{18}$ The $\mathbf{P t L}{ }^{1} \mathbf{C l}$ complex was readily converted into PtL ${ }^{1} \mathbf{N C S}$ upon treatment with sodium thiocyanate in methanol-dichloromethane at room temperature. The two new ligands and their $\mathrm{Pt}(\mathrm{II})$ complexes were fully characterized by elemental analysis, mass spectrometry and NMR spectroscopy. ${ }^{1} \mathrm{H}$ NMR spectroscopy confirms that the $E$ (trans) configuration of the $\mathrm{C}=\mathrm{C}$ double bond of $\mathbf{H L}^{2}$ is retained in the complex $\mathbf{P t} \mathbf{L}^{2} \mathbf{C l}$.

Interestingly it turned out that complex $\mathbf{P t} \mathbf{L}^{2} \mathbf{C l}$, in solution in $\mathrm{CH}_{2} \mathrm{Cl}_{2}$ at room temperature, readily isomerizes to give the cis isomer upon exposure to ambient light, as revealed by the evolution of the ${ }^{1} \mathrm{H}$ NMR spectrum (data are provided in Fig. S1 of the ESI $\dagger$ ). The cis isomer reconverts into the thermodynamically more stable trans isomer in the dark at room temperature (Scheme 2). In contrast, no cis isomer is formed when a solid sample of $\mathbf{P t L}^{2} \mathbf{C l}$ is left under solar light at room temperature for at least a few months.

\section{Photophysical properties in solution}

Absorption and photoluminescence data of the uncoordinated proligands and of the three $\mathrm{Pt}(\mathrm{II})$ complexes are presented in Table 1.

Proligands $\mathbf{H L}^{1}$ and $\mathbf{H L}^{2}$. The absorption spectra of the proligands (Fig. 1) show very intense bands in the UV region $(\lambda<400 \mathrm{~nm})$, due to spin-allowed ${ }^{1} \pi-\pi^{*}$ transitions. Both compounds are intensely fluorescent in solution at room temperature (Fig. 1): $\mathbf{H L}^{\mathbf{1}}$ emits in the blue region of the spectrum $\left(\lambda_{\max }=430 \mathrm{~nm}\right)$ with a luminescence quantum yield $\Phi$ of 0.82 , whilst the emission of $\mathbf{H L}^{2}$ is blue-green, being somewhat red-shifted compared to that of $\mathbf{H L}^{\mathbf{1}}\left(\lambda_{\max }=459 \mathrm{~nm}, \Phi=0.92\right)$. At $77 \mathrm{~K}, \mathbf{H L}^{1}$ shows, in addition to the fluorescence band, a set of structured phosphorescence bands in the 500-600 mm region, characterised by a very long lifetime approaching $1 \mathrm{~s}$. In contrast, no phosphorescence is detectable for $\mathbf{H L}^{2}$.

Platinum complexes. The UV-visible absorption spectra of the new complexes $\mathbf{P t L}^{1} \mathbf{C l}$ and $\mathbf{P t L}^{1} \mathbf{N C S}$ in dichloromethane solution at room temperature (Fig. 2 and $\mathrm{S} 2 \dagger$ ) show intense bands at $\lambda<300 \mathrm{~nm}$ and another set of bands in the $330-400 \mathrm{~nm}$ region that are only a little less intense than the higher energy ones. Indeed, the spectra are fairly similar to those of $\mathbf{H L}^{\mathbf{1}}$. They differ from those normally displayed by simple cyclometallated $\mathrm{Pt}(\mathrm{II})$ complexes with arylpyridine ligands, such as $\mathrm{Pt}(\mathrm{dpyb}) \mathrm{Cl}$ (dpyb = cyclometallated 1,3-di(2-pyridyl)benzene), in that the lower-energy bands are so intense.

Typically in complexes such as $\mathrm{Pt}(\mathrm{dpyb}) \mathrm{Cl}$, bands in the 350$400 \mathrm{~nm}$ region have $\varepsilon$ values of around $7000 \mathrm{M}^{-1} \mathrm{~cm}^{-1}$, with no counterparts in the proligands, assigned to metal-to-ligand and intra-ligand charge-transfer transitions that are introduced upon cyclometallation. ${ }^{5,21}$ Such transitions will necessarily be present in the current complexes, but they are evidently superimposed on intense ligand-centred transitions. This leads to unusually high $\varepsilon$ values in this region, around 3-4 times higher than in Pt(dpyb)Cl.

Both PtL ${ }^{1} \mathbf{C l}$ and PtL $^{1}$ NCS complexes are intensely luminescent in dilute solution at room temperature, displaying

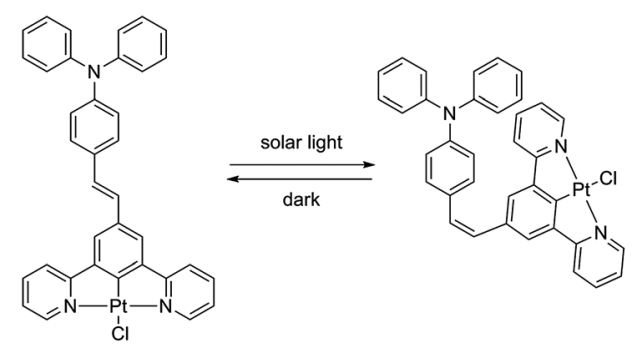

Scheme 2 Trans-cis isomerisation of complex $\mathrm{PtL}^{2} \mathrm{Cl}$. 
Table 1 Photophysical data of the free ligands $\mathrm{HL}^{1}, \mathrm{HL}^{2}$ and related $\mathrm{Pt}(॥)$ complexes

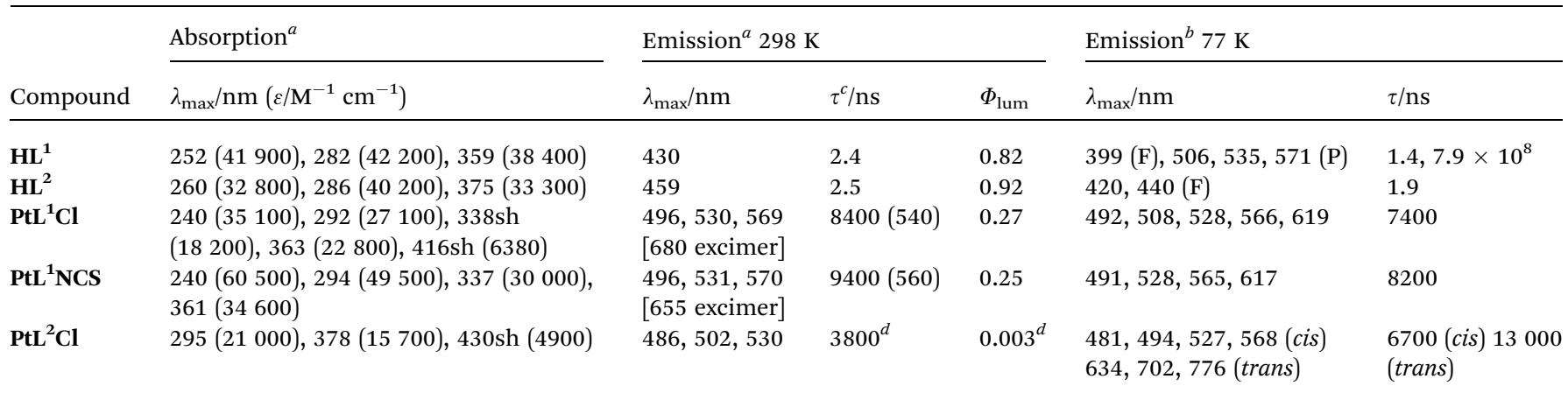

${ }^{a}$ In degassed $\mathrm{CH}_{2} \mathrm{Cl}_{2} \cdot{ }^{b}$ In diethyl ether-isopentane-ethanol $(2: 2: 1 \mathrm{v} / \mathrm{v}) .{ }^{c}$ The lifetime values indicated for $\mathbf{P t L}{ }^{\mathbf{1}} \mathbf{C l}$ and $\mathbf{P t L}{ }^{\mathbf{1}} \mathbf{N C S}$ are those at infinite dilution, obtained from a plot of $\tau^{-1}$ versus concentration, as described previously. ${ }^{9 a, 21 a}$ The values in parenthesis are for air-equilibrated solution. ${ }^{d}$ Quantum yield and lifetime at the photostationary state formed upon irradiation with the UV lamp at $365 \mathrm{~nm}$; emissive due to the cis form.
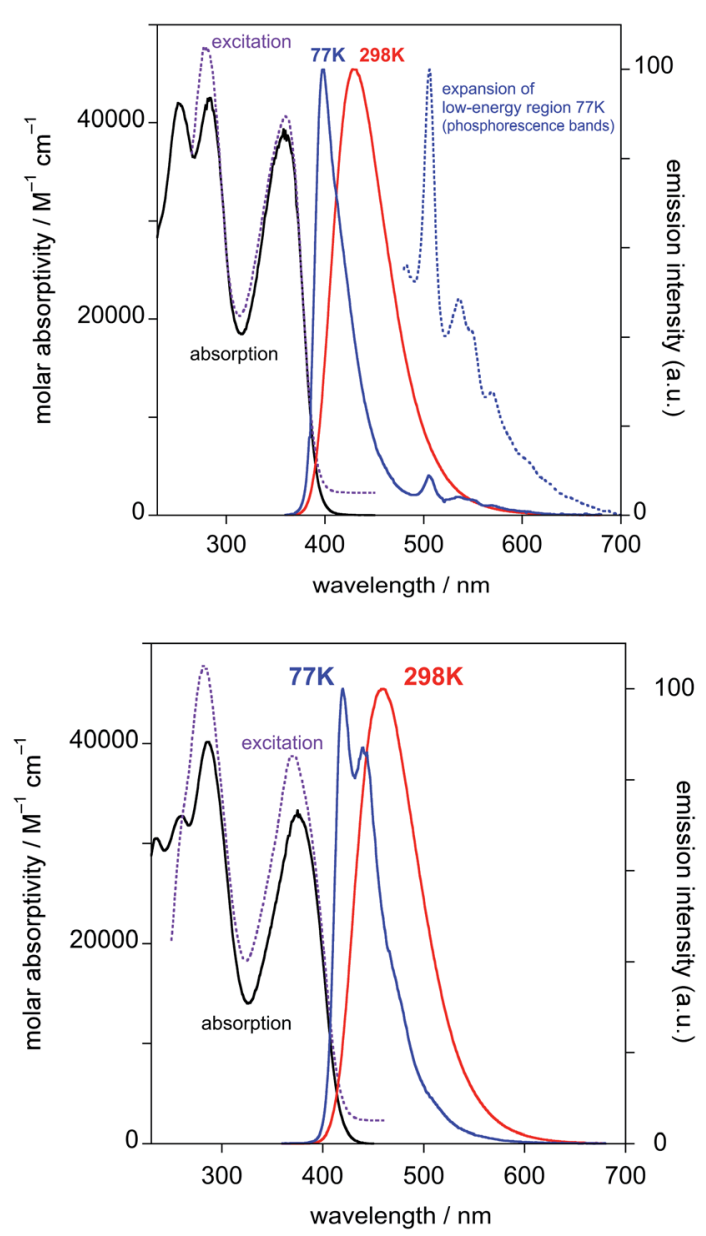

Fig. 1 Absorption (black), excitation (dashed purple), and emission (red lines) spectra of $\mathrm{HL}^{1}$ (top) and $\mathrm{HL}^{2}$ (bottom) in $\mathrm{CH}_{2} \mathrm{Cl}_{2}$ at $298 \mathrm{~K}$ and their emission spectra at $77 \mathrm{~K}$ in diethyl ether-isopentane-ethanol $(2: 2: 1 \mathrm{v} / \mathrm{v})$ (blue lines).

vibrationally structured emission spectra with maxima in the green region at $496 \mathrm{~nm}$ and luminescence quantum yields of around 0.25 (Table 1 and Fig. 2; spectra for $\mathbf{P t L}^{1} \mathbf{N C S}$ are shown in Fig. S2 in the ESI $\dagger$ ). The profile of the spectra, attributed to a

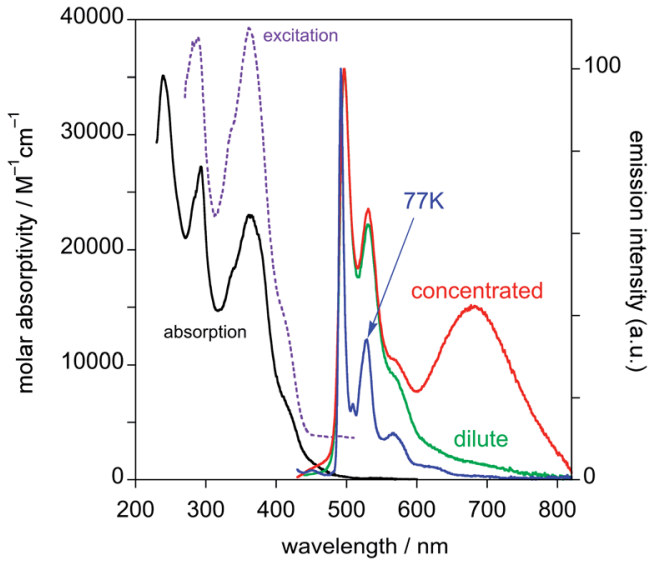

Fig. 2 Absorption and excitation $\left(\lambda_{\mathrm{em}}=530 \mathrm{~nm}\right.$ ) spectra of $\mathrm{PtL}{ }^{1} \mathrm{Cl}$ in $\mathrm{CH}_{2} \mathrm{Cl}_{2}$ at $298 \mathrm{~K}$ (solid black and dashed purple lines); emission spectra under the same conditions for solutions of concentration $1.8 \times 10^{-5} \mathrm{M}$ (green line) and $3.2 \times 10^{-4} \mathrm{M}$ (red line) and emission spectrum at $77 \mathrm{~K}$ in diethyl ether-isopentane-ethanol (2:2:1 v/v) (blue line).

primarily ligand-centred ${ }^{3} \pi-\pi^{*}$ state, is in each case similar to that of the parent complex $\mathrm{Pt}(\mathrm{dpyb}) \mathrm{Cl}$, as are the luminescence lifetimes of around $8 \mu \mathrm{s} .{ }^{9}$

Like the parent complex, $\mathbf{P t L}^{1} \mathbf{C l}$ and $\mathbf{P t L}{ }^{\mathbf{1}} \mathbf{N C S}$ readily form excimers at elevated concentration in solution, which emit in the red region of the spectrum. Interestingly, although the change of the monodentate ligand from $\mathrm{Cl}^{-}$to $\mathrm{NCS}^{-}$has no significant influence on the emission wavelength of the monomeric complex, the excimer emission of PtL $^{1} \mathbf{N C S}$ is somewhat blue-shifted relative to that of $\mathbf{P t L}{ }^{1} \mathbf{C l}\left(\lambda_{\max }=655\right.$ and $680 \mathrm{~nm}$, respectively). The formation of the excimer is accompanied by the expected decrease in relative intensity of the monomer bands, whilst the luminescence lifetime decreases. The gradients of the plots of the observed radiative rate constant $(=1 / \tau)$ versus concentration provide an indication of the propensity of such complexes to form excimers. The values of $1.9 \times 10^{9}$ and $3.6 \times 10^{9} \mathrm{M}^{-1} \mathrm{~s}^{-1}$ are of the same order of magnitude as those found for 5-aryl-substituted derivatives of the parent $\mathrm{Pt}(\mathrm{dpyb}) \mathrm{Cl}^{21}$ 
The behaviour of $\mathbf{P t L}^{\mathbf{2}} \mathbf{C l}$, the complex incorporating the styryl substituent, is more complicated. In dichloromethane solution at $298 \mathrm{~K}$, its absorption spectrum shows significant absorption to somewhat longer wavelengths than the alkynyl complexes PtL ${ }^{1} \mathrm{X}$ (Fig. 3 and Table 1), but the spectrum rapidly changes in daylight or upon irradiation in the near-UV, losing the long-wavelength absorption tail. A change in the absorption spectrum upon irradiation is consistent with the light-activated trans to cis isomerisation observed by ${ }^{1} \mathrm{H}$ NMR spectroscopy described above. Around 7-10 minutes with a standard laboratory hand-held UV lamp $(6 \mathrm{~W}, \lambda=365 \mathrm{~nm})$ is sufficient to reach a photostationary state. Apparently, then, the lowestenergy spin-allowed transitions of the trans form of the complex must be lower in energy than those of the cis form.

This tentative conclusion from the experimental data is supported by the results of time-dependent density functional theory (TD-DFT) calculations, carried out as described in the Experimental section. Examination of the 20 lowest-energy spin-allowed transitions at the ground-state geometry reveals that the cis form is indeed predicted to be blue-shifted relative to the trans (the simulated spectra using the ten lowest-energy singlet transitions are provided in Fig. S3†). The density difference plots for the lowest-energy singlet states show a significant degree of intraligand charge-transfer character from the styryl pendant to the dipyridylbenzene moiety (see Fig. S4 in the ESI $\dagger$ ).

The photoluminescence also changes upon irradiation. The main observations can be summarised as follows:

(i) Before irradiation, the complex shows weak green phosphorescence in solution at room temperature when excited at wavelengths less than about $430 \mathrm{~nm}$ (Fig. 4). The structured emission profile, with the $0-0$ vibrational band highest in intensity, is similar to that of $\mathrm{Pt}(\mathrm{dpyb}) \mathrm{Cl}^{., 21 a}$

(ii) Excitation into the long-wavelength absorption tail at $\lambda>$ $450 \mathrm{~nm}$ gives no emission. Indeed, it can be seen that the excitation spectrum registered at $\lambda=530 \mathrm{~nm}$ lacks the lowenergy tail that was observed in the absorption spectrum prior to irradiation.

(iii) After irradiation for $7 \mathrm{~min}$ with the UV lamp, the emission in the green region substantially increases in intensity (Fig. 4).

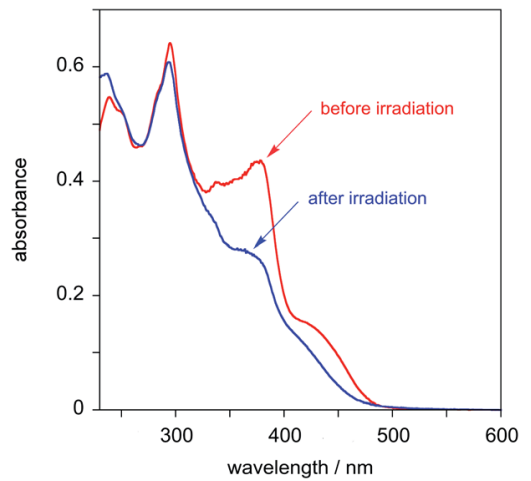

Fig. 3 Absorption spectra of $\mathrm{PtL}^{2} \mathrm{Cl}$ in $\mathrm{CH}_{2} \mathrm{Cl}_{2}$ at $298 \mathrm{~K}$ before (red) and after (blue) irradiation with a UV lamp for 7 minutes.

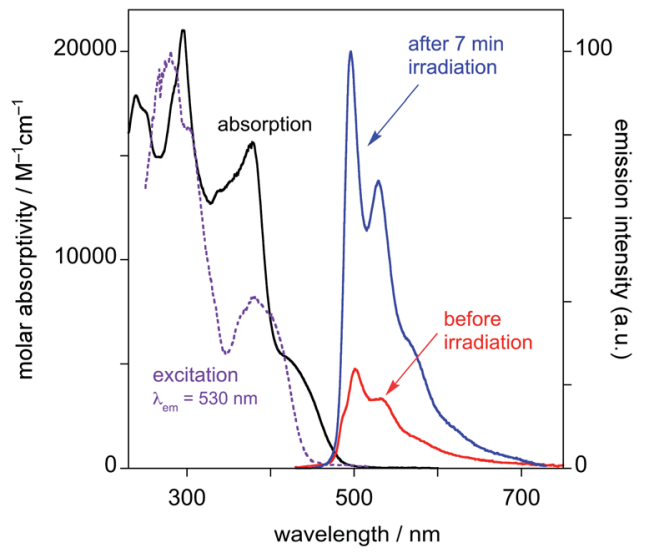

Fig. 4 Emission spectra of $\mathrm{PtL}^{2} \mathrm{Cl}$ in $\mathrm{CH}_{2} \mathrm{Cl}_{2}$ at $298 \mathrm{~K}$ before and after irradiation with a UV lamp for 7 minutes $\left(\lambda_{\text {ex }}=415 \mathrm{~nm}\right)$.

(iv) At $77 \mathrm{~K}$ in frozen glass (diethyl ether-iso-pentaneethanol), the emission spectrum displays a set of vibrationally structured bands in the range $600-800 \mathrm{~nm}$. Following irradiation (in solution at room temperature), and re-recording of the spectrum at $77 \mathrm{~K}$, a new set of bands appears in the range 480$600 \mathrm{~nm}$, the typical region for $\mathrm{Pt}(\mathrm{dpyb}) \mathrm{Cl}$ and its simple 5-alkyl derivatives, ${ }^{9,21 a}$ and the lower-energy bands lose intensity (Fig. 5).

We interpret these observations through the following assignments to the emission bands:

(A) The higher-energy emission in the 480-600 $\mathrm{nm}$ region can be attributed to the cis isomer of $\mathbf{P t L}^{2} \mathbf{C l}$, which emits - both at room temperature and at $77 \mathrm{~K}-$ much like $\mathrm{Pt}(\mathrm{dpyb}) \mathrm{Cl}$ and other derivatives with simple substituents in the 5-position of the aryl ring (e.g., $\left.\mathbf{P t L}^{\mathbf{1}} \mathbf{C l}\right)$.

(B) The lower-energy bands in the 600-800 $\mathrm{nm}$ region which are observed at $77 \mathrm{~K}$ only - can be assigned to the trans isomer, which shows no emission at room temperature in solution.

This assignment accounts for (i) the lack of emission in solution at room temperature upon excitation at $\lambda>450 \mathrm{~nm}$, where the cis form does not absorb; (ii) the appearance of higher-energy bands (cis form) in the $77 \mathrm{~K}$ spectrum after irradiation and (iii) the increase in the room temperature emission intensity upon irradiation, as the cis form builds up. The fact that there is some emission from solution even before

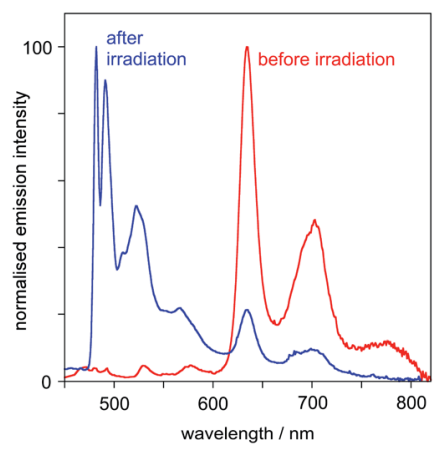

Fig. 5 Emission spectra of $\mathrm{PtL}^{2} \mathrm{Cl}$ at $77 \mathrm{~K}$ in diethyl ether-isopentaneethanol $(2: 2: 1 \mathrm{v} / \mathrm{v})$ before and after UV irradiation. 
deliberate irradiation is probably due to the fact that isomerisation will occur as soon as the sample is exposed to the excitation source required to record the emission spectrum, and to the inevitable presence of some cis isomer formed as the sample is prepared. The observed low luminescence quantum yield observed for $\mathbf{P t L}^{2} \mathbf{C l}$ in solution even in the cis form may be due to the competitive formation of a non-emissive excited state with a half-twisted conformation of the $\mathrm{C}=\mathrm{C}$ unit. Similarly poor quantum yields were previously observed for a series of styryl-appended Pt(ppy)(acac) complexes, attributed to such a process. $^{24}$

TD-DFT calculations are again informative in helping to understand the differing behaviour of the cis and trans forms. Fig. 6 shows the density difference plots for the lowest-energy triplet $\left(\mathrm{T}_{1}\right)$ excited states of the two isomers, calculated at their triplet-state geometries. It can be seen that the triplet excited state of the cis form is largely located on the $\mathrm{Pt}\left(\mathrm{N}^{\wedge} \mathrm{C}^{\wedge} \mathrm{N}\right) \mathrm{Cl}$ moiety, with little involvement of the pendant. Indeed, the orbital parentage of the excited state is similar to that of the parent complex Pt(dpyb)Cl obtained using comparable calculations, ${ }^{\mathbf{2 1 b}}$ consistent with the observation that the emission energy and the spectral profile of $c$ is-PtL ${ }^{2} \mathbf{C l}$ are similar to those of the parent. In contrast, the density difference plot for the triplet state of trans$\mathbf{P t L}^{2} \mathbf{C l}$ spans the metallated aryl ring, the $\mathrm{C}=\mathrm{C}$ bond, and the pendent aniline unit (Fig. 6). There is a more extended conjugated unit, consistent with the unusually low emission energy compared to $\mathrm{Pt}(\mathrm{dpyb}) \mathrm{Cl}$. Indeed, it is notable that the emission energy is not dissimilar to that of $E$-stilbene phosphorescence $\left(\lambda_{\max }=580 \mathrm{~nm}\right) .{ }^{25}$ It is also apparent from the density difference

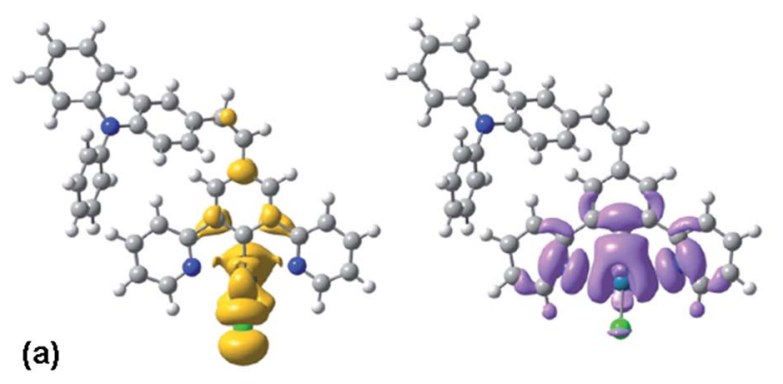

(b)
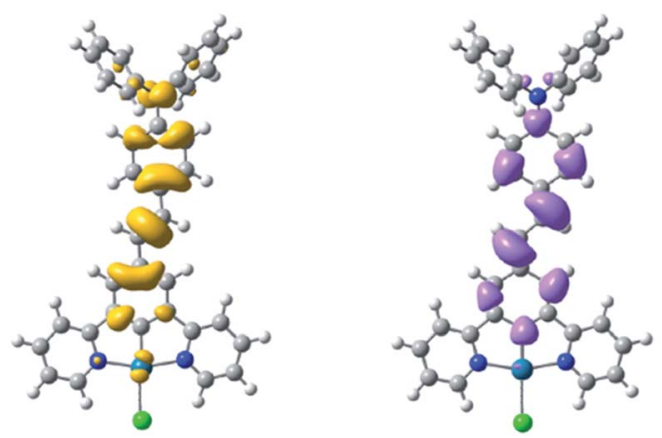

Fig. 6 Density difference plots for the lowest triplet excitations of the cis (a) and trans (b) forms of $\mathrm{PtL}^{2} \mathrm{Cl}$ calculated at the optimised $\mathrm{T}_{1}$ geometry, using PBEO with the PCM model for $\mathrm{CH}_{2} \mathrm{Cl}_{2}$. Yellow and purple represent zones of depletion and augmentation of electron density in the $T_{1}$ excited state versus the $S_{0}$ ground state. plot that metal orbitals seem to play a more minor role in the excited state compared to the cis. This might account for the longer lifetime of the emission bands of the trans compared to the cis form at $77 \mathrm{~K}$ (13 and $6.7 \mu$ s respectively, Table 1$)$, since it is the influence of the metal that promotes the formally forbidden $\mathrm{T}_{1} \rightarrow \mathrm{S}_{0}$ phosphorescence process.

\section{OLED characterization}

The three new complexes $\mathbf{P t L}^{\mathbf{1}} \mathbf{C l}, \mathbf{P t L} \mathbf{L}^{\mathbf{1}} \mathbf{N C S}$, and $\mathbf{P t L}^{\mathbf{2}} \mathbf{C l}$ were examined as phosphors for OLEDs, in the form of neat films, where the intermolecular interactions might be expected to become important. OLEDs were fabricated by growing a sequence of thin layers on glass substrates pre-coated with indium tin oxide (ITO), transparent to the light generated in the emitting layer (EML) (see Experimental section for details). Holes were injected from the ITO/ $\mathrm{Mo}_{2} \mathrm{O}_{x}$ anode, and passed through a $80 \mathrm{~nm}$ thick hole-transporting layer composed of TCTA. They recombine in the EML $(15 \mathrm{~nm}$ thick layer of the pure $\mathrm{Pt}(\mathrm{II})$ complex) with electrons injected from an $\mathrm{Al} / \mathrm{LiF}$ cathode and transported through a $25 \mathrm{~nm}$ layer of TPBi $(1,3,5-\operatorname{tris}(N$ phenyl-benzimidazol-2-yl)benzene).

Fig. 7 and 8 show the plots of luminance and electroluminescence intensity, respectively, versus voltage for the OLEDs prepared with the neat platinum(II) complexes as emitting layers, whilst Fig. 9 shows the electroluminescence quantum efficiencies (EL QE) versus the electric current density. Clearly, although the three complexes have a similar brightness and electroluminescence intensity, $\mathbf{P t L}^{2} \mathbf{C l}$ is the best candidate for the preparation of OLEDs, since its device is characterized by a high electroluminescence quantum efficiency (QE). The much lower QE of the devices incorporating $\mathbf{P t L}^{1} \mathbf{C l}$ and $\mathbf{P t L}^{1} \mathbf{N C S}$ can be attributed to some degradation, as confirmed by the unstable electroluminescence spectra of the related OLEDs (see ESI $\dagger$ ).

The electroluminescence spectrum of the OLED based on neat $\mathbf{P t L}^{2} \mathbf{C l}$ as an emitting layer is stable (all measurements were reproduced for many runs, excluding any irreversible chemical and morphological changes in the devices) and it exhibits a very broad, low-energy, structureless band around

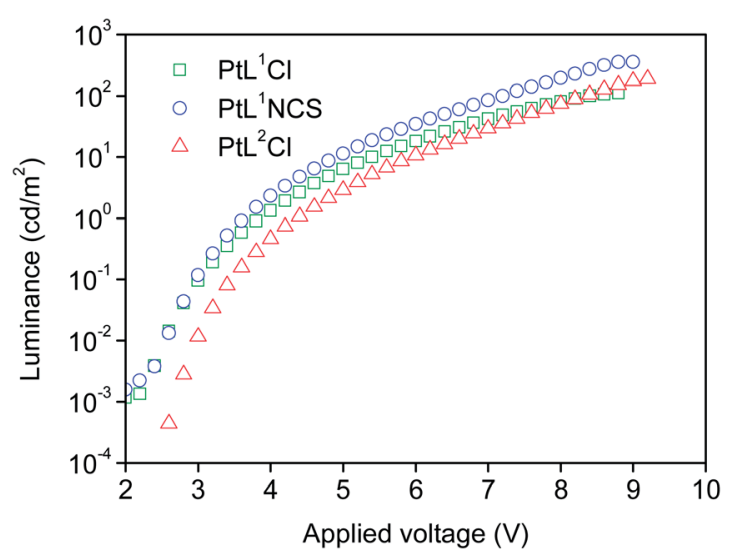

Fig. 7 Luminance versus applied voltage of the OLEDs using the neat complexes as emitting layers. The device incorporating $\mathrm{PtL}^{1} \mathrm{Cl}$ is shown in green, $\mathrm{PtL}^{1} \mathrm{NCS}$ is in blue, and $\mathrm{PtL}^{2} \mathrm{Cl}$ in red. 


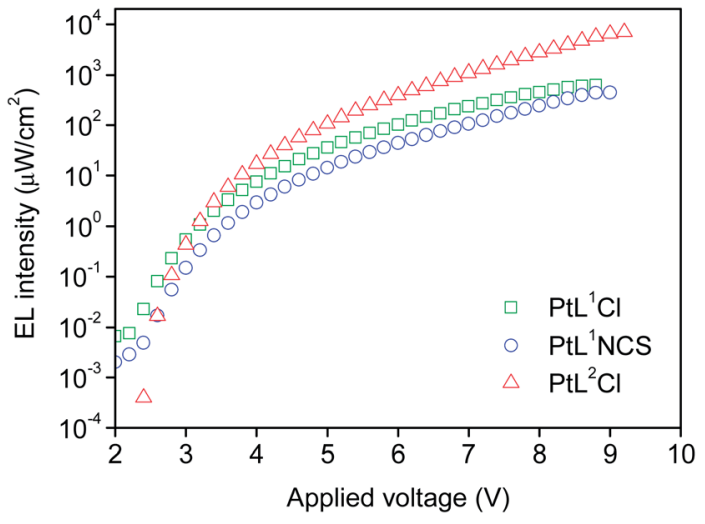

Fig. 8 Electroluminescence intensity versus applied voltage of the OLEDs using the neat complex as EML; colours as in Fig. 7.

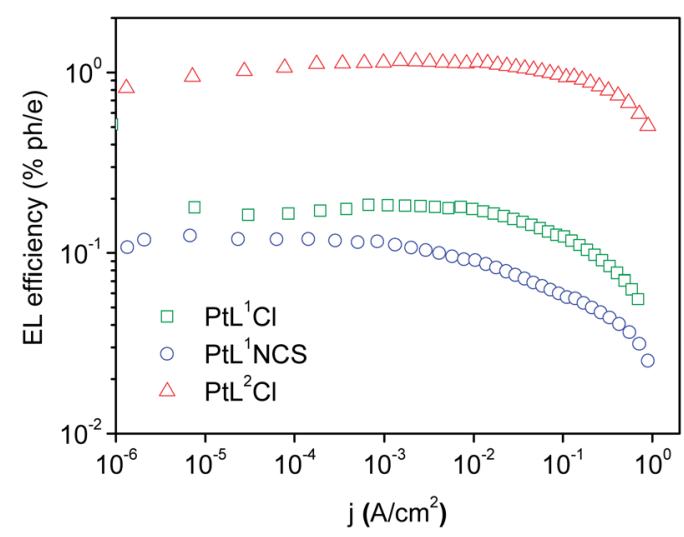

Fig. 9 External quantum efficiencies versus electric current density for the OLEDs using the neat complex as EML; colours as in Fig. 8.

$800 \mathrm{~nm}$ (Fig. 10), described by CIE coordinates $x=0.673$ and $y=$ 0.315 .

This spectrum is very different from that typical of devices based on other reported platinum(II) derivatives with cyclometallated 1,3-di(2-pyridyl)benzene ligands, which exhibit excimer-like emission from neat films, with $\lambda_{\max }$ around 685 nm. ${ }^{5 c, d, g}$ Such an EL spectrum, drastically shifted into the NIR spectral region, is of particular interest for these kinds of complexes. A comparably low-energy emission has been previously observed only for $\mathrm{PtL}^{\mathrm{mes}} \mathrm{NCS}$, as mentioned in the Introduction. ${ }^{16}$ As in the latter complex, the metal-metal interactions within the neat film apparently lead to the formation of lowenergy aggregates that emit in the NIR region. The NIR OLED shows the best performance with an EL intensity of about 10 $\mathrm{mW} \mathrm{cm} \mathrm{cm}^{-2}$ at $9 \mathrm{~V}$ and a maximum $\mathrm{QE}$ of $1.2 \% \mathrm{ph} / \mathrm{e}$ at a current density of $10 \mathrm{~mA} \mathrm{~cm}{ }^{-2}$. It is worth noting that the QE of this device remains fairly constant over a wide range of current density from $10^{-3}$ to $400 \mathrm{~mA} \mathrm{~cm}{ }^{-2}$.

On the other hand, the EL spectra of the OLEDs with $5 \mathrm{wt} \%$ of $\mathbf{P t L}^{2} \mathbf{C l}$ in TCTA or CBP are quite similar to one another and are clearly characterized by emission from the monomolecular excited states of the trans isomer around $600 \mathrm{~nm}$ together with a contribution of the TCTA or CBP emission bands (Fig. 10, blue

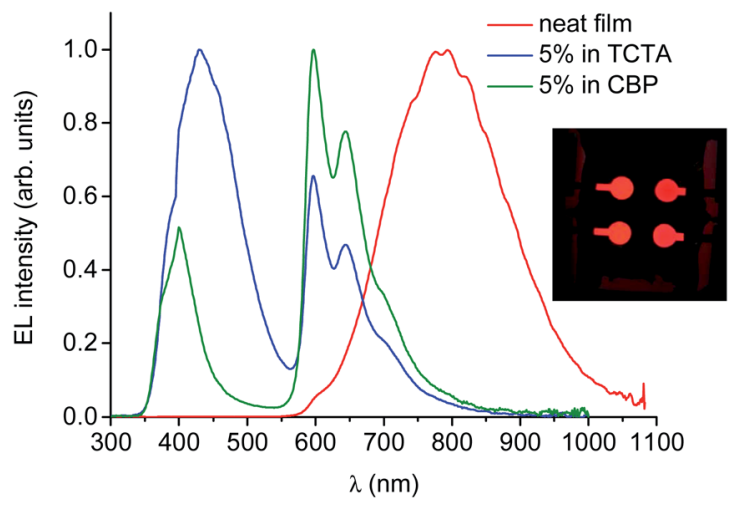

Fig. 10 Electroluminescence spectra of OLEDs incorporating $\mathrm{PtL}^{2} \mathrm{Cl}$ as a neat film or doped in TCTA or CBP as the emitting layer at $8 \mathrm{~V}$. Photo of the NIR-OLEDs (inset).

and green lines respectively). The CIE coordinates are $x=0.302$, $y=0.203$ and $x=0.537, y=0.203$ for films in TCTA and CBP, respectively. The plots of luminescence versus applied voltage and external quantum efficiencies versus electric current density are shown in the ESI. $\dagger$

\section{Conclusions}

In summary, we have prepared and characterized two new highly luminescent $\mathrm{N}^{\wedge} \mathrm{C}^{\wedge} \mathrm{N}$ pincer ligands incorporating triple $\mathrm{ArC} \equiv \mathrm{C}-\left(\mathbf{H L}^{\mathbf{1}}\right)$ or double $\mathrm{ArCH}=\mathrm{CH}-\left(\mathbf{H L}^{2}\right)$ bonds at the 5-position of the central aryl ring, together with their cyclometallated platinum(II) complexes $\mathrm{PtL}^{1} \mathrm{X}(\mathrm{X}=\mathrm{Cl}$, NCS) and $\mathbf{P t L}^{2} \mathbf{C l}$. Complexes $\mathrm{PtL}^{1} \mathrm{X}$ display high photoluminescence quantum yields in solution. They also have much higher molar absorptivities than the parent complex $\mathrm{Pt}(\mathrm{dpyb}) \mathrm{Cl}$ and its simple 5-aryl derivatives, the $\varepsilon$ values in the $350-400 \mathrm{~nm}$ region being around 3-4 times greater. In the field of luminescent probes, for example in bioimaging and sensing, it is currently popular to refer to a "brightness" index, which is the product of the extinction coefficient and quantum yield, reflecting the importance of both quantities in determining suitability for practical use. ${ }^{26}$ In the case of the new complexes $\mathrm{PtL}^{1} \mathrm{X}$, although the quantum yield is somewhat compromised compared to the parent (factor of 2), it is clear that their brightness would be significantly superior owing to the beneficial effect of the substituent on the $\varepsilon$ values.

Contrary to the $\mathrm{C} \equiv \mathrm{C}$-substituted complexes, the photoluminescence quantum yield of $\mathbf{P t} \mathbf{L}^{2} \mathbf{C l}$ is very low in solution at room temperature, due to competitive photoinduced trans-to-cis isomerisation of the diphenyl-aminostyryl $\mathrm{C}=\mathrm{C}$ bond.

OLEDs have been prepared using the new compounds as phosphorescent emitters. Remarkably, the best electroluminescence quantum efficiencies are obtained with $\mathbf{P t L}^{2} \mathbf{C l}$. The isomerisation process observed under photoexcitation evidently does not occur in the emissive layer under electrically driven conditions. This study highlights how photoluminescence performance in solution is not necessarily a good guide to electroluminescence efficiency in a device. 
$\mathbf{P t L}^{2} \mathbf{C l}$ appears as an excellent candidate for the preparation of NIR-OLEDs. The electroluminescence intensity of the studied NIR-OLED is three times higher than the previously reported NIR-OLED based on a neat film of $\mathrm{PtL}^{\text {mes }} \mathrm{NCS},{ }^{16}$ whilst the maximum external quantum efficiency is enhanced by $20 \%$. The stability and the limited efficiency-roll-off of the NIR-OLED at high current density are good characteristics for applications requiring high NIR intensity. NIR-emitting systems have diverse potential applications, including communications and night vision-readable displays, as well as offering superior biocompatibility for medical systems since biological tissue is most transparent to light in the NIR.

\section{Acknowledgements}

This work was supported in Italy by MIUR (FIRB 2004: RBPR05JH2P) and Consorzio MIST E-R (project FESR-Tecnopolo AMBIMAT), and in the U.K. by EPSRC (EP/G06928X/1).

\section{Notes and references}

1 M. A. Baldo, D. F. O'Brien, Y. You, A. Shoustikov, S. Sibley, M. E. Thompson and S. R. Forest, Nature, 1998, 395, 151.

2 (a) Highly Efficient OLEDs with Phosphorescent Materials, ed. H. Yersin, Wiley-VCH, Weinheim, 2008; (b) Organic lightemitting diodes: Materials, devices and applications, ed. A. Buckley, Woodhead, Cambridge, 2013.

3 (a) Y. Chi and P.-T. Chou, Chem. Soc. Rev., 2010, 39, 638; (b) P.-T. Chou, Y. Chi, M.-W. Chung and C.-C. Lin, Coord. Chem. Rev., 2011, 255, 2653; (c) G. Zhou, W.-Y. Wong and X. L. Yang, Chem. - Asian J., 2011, 6, 1706; (d) C. L. Ho and W.-Y. Wong, New J. Chem., 2013, 37, 1665.

4 For reviews, see for example: (a) D. R. McMillin and J. J. Moore, Coord. Chem. Rev., 2002, 229, 113; (b) S.-W. Lai and C.-M. Che, Top. Curr. Chem., 2004, 241, 27; (c) B. Ma, P. Djurovich and M. E. Thompson, Coord. Chem. Rev., 2005, 249, 1501; (d) F. N. Castellano, I. E. Pomestchenko, E. Shikhova, F. Hua, M. L. Muro and N. Rajapakse, Coord. Chem. Rev., 2006, 250, 1819; (e) K. M.-C. Wong and V. W.-W. Yam, Coord. Chem. Rev., 2007, 251, 2477; (f) J. A. G. Williams, Top. Curr. Chem., 2007, 281, 205; $(g)$ J. A. G. Williams, S. Develay, D. L. Rochester and L. Murphy, Coord. Chem. Rev., 2008, 252, 2596; (h) W.-Y. Wong and C.-L. Ho, Coord. Chem. Rev., 2009, 253, 1709; (i) A. F. Rausch, H. H. H. Homeier and H. Yersin, Top. Organomet. Chem., 2010, 29, 193; (j) Y. Chi and P.-T. Chou, Chem. Soc. Rev., 2010, 39, 638; (k) L. Murphy and J. A. G. Williams, Top. Organomet. Chem., 2010, 28, 75; (l) C. A. Strassert, C.-H. Chien, M. D. Galvez Lopez, D. Kourkoulos, D. Hertel, K. Meerholz and L. De Cola, Angew. Chem., Int. Ed., 2011, 50, 946; (m) J. Kalinowski, V. Fattori, M. Cocchi and J. A. G. Williams, Coord. Chem. Rev., 2011, 255, 2401.

5 Recent examples with Pt(II) include: (a) A. Y.-Y. Tam, D. P.-K. Tsang, M. Y. Chan, N. Y. Zhu and V. W.-W. Yam, Chem. Commun., 2011, 47, 3383; (b) C. A. Strassert, C.-H. Chien, M. D. Galvez Lopez, D. Kourkoulos, D. Hertel,
K. Meerholz and L. De Cola, Angew. Chem., Int. Ed., 2011, 50, 946; (c) W. Mroz, C. Botta, U. Giovanella, E. Rossi, A. Colombo, C. Dragonetti, D. Roberto, R. Ugo, A. Valore and J. A. G. Williams, J. Mater. Chem., 2011, 21, 8653; (d) E. Rossi, L. Murphy, P. L. Brothwood, A. Colombo, C. Dragonetti, D. Roberto, R. Ugo, M. Cocchi and J. A. G. Williams, J. Mater. Chem., 2011, 21, 15501; (e) V. N. Kozhevnikov, M. C. Durrant and J. A. G. Williams, Inorg. Chem., 2011, 50, 6304; $(f)$ S. C. F. Hui, P. K. Chow, G. S. M. Tong, S.-L. Lai, G. Cheng, C.-C. Kwok, K.-H. Low, M. Y. Ko and C.-M. Che, Chem. - Eur. J., 2013, 19, 69; (g) E. Rossi, A. Colombo, C. Dragonetti, D. Roberto, R. Ugo, A. Valore, L. Falciola, P. Brulatti, M. Cocchi and J. A. G. Williams, J. Mater. Chem., 2012, 22, 10650; (h) J. Zhang, F. C. Zhao, X. J. Zhu, W.-K. Wong, D. G. Ma and W.-Y. Wong, J. Mater. Chem., 2012, 22, 16448; (i) N. K. Allampally, C. A. Strassert and L. De Cola, Dalton Trans., 2012, 41, 13132; (j) X.-C. Hang, T. Fleetham, E. Turner, J. Brooks and J. Li, Angew. Chem., Int. Ed., 2013, 52, 6753; ( $k$ ) E. Turner, N. Bakken and J. Li, Inorg. Chem., 2013, 52, 7344; (l) S. Culham, P.-H. Lanoë, V. L. Whittle, M. C. Durrant, J. A. G. Williams and V. N. Kozhevnikov, Inorg. Chem., 2013, 52, 10992.

6 (a) D. R. McMillin and J. J. Moore, Coord. Chem. Rev., 2002, 229, 113; (b) R. McGuire, Jr, M. C. McGuire and D. R. McMillin, Coord. Chem. Rev., 2010, 254, 2574.

7 (a) A. F. Rausch, L. Murphy, J. A. G. Williams and H. Yersin, Inorg. Chem., 2009, 48, 11407; (b) A. F. Rausch, L. Murphy, J. A. G. Williams and H. Yersin, Inorg. Chem., 2012, 51, 312; (c) L. Murphy, P. Brulatti, V. Fattori, M. Cocchi and J. A. G. Williams, Chem. Commun., 2012, 48, 5817.

8 D. J. Cardenas, A. M. Echavarren and M. C. Ramirez de Arellano, Organometallics, 1999, 18, 3337.

9 (a) J. A. G. Williams, A. Beeby, E. S. Davies, J. A. Weinstein and C. Wilson, Inorg. Chem., 2003, 42, 8609; (b) J. A. G. Williams, Chem. Soc. Rev., 2009, 38, 1783.

10 E. Rossi, A. Colombo, C. Dragonetti, S. Righetto, D. Roberto, R. Ugo, A. Valore, J. A. G. Williams, M. G. Lobello, F. De Angelis, S. Fantacci, I. Ledoux-Rak, A. Singh and J. Zyss, Chem. - Eur. J., 2013, 19, 9875.

11 M. Cocchi, D. Virgili, V. Fattori, D. L. Rochester and J. A. G. Williams, Adv. Funct. Mater., 2007, 17, 285.

12 E. M. Kober, J. V. Caspar, R. S. Lumpkin and T. J. Meyer, J. Phys. Chem., 1986, 90, 3722.

13 (a) J. Kido and Y. Okamoto, Chem. Rev., 2002, 102, 2357; (b) A. O'Riordan, E. O'Connor, S. Moynihan, P. Nockemann, P. Fias, R. Van Deun, D. Cupertino, P. Mackie and G. Redmond, Thin Solid Films, 2006, 497, 299.

14 (a) C. Borek, K. Hanson, P. I. Djurovich, M. E. Thompson, K. Aznavour, R. Bau, Y. Sun, S. R. Forrest, J. Brooks, L. Michalski and J. Brown, Angew. Chem., Int. Ed., 2007, 46, 1109; (b) Y. Sun, C. Borek, K. Hanson, P. I. Djurovich, M. E. Thompson, J. Brooks and J. Brown, Appl. Phys. Lett., 2007, 90, 213503.

15 (a) W. Lu, M. C. W. Chan, N. Zhu, C. M. Che, C. Li and Z. Hui, J. Am. Chem. Soc., 2004, 126, 7639; (b) J. Kalinowski, M. Cocchi, L. Murphy, J. A. G. Williams and V. Fattori, Chem. Phys., 2010, 378, 47. 
16 E. Rossi, A. Colombo, C. Dragonetti, D. Roberto, F. Demartin, M. Cocchi, P. Brulatti, V. Fattori and J. A. G. Williams, Chem. Commun., 2012, 48, 3182.

17 E. Diez-Barra, J. C. Garcia-Martinez, S. Merino, R. del Rey, J. Rodrìguez-Lòpez, P. Sànchez-Verdù and J. Tejeda, J. Org. Chem., 2001, 66, 5664.

18 Z. Wang, E. Turner, V. Mahoney, S. Madakuni, T. Groy and J. Li, Inorg. Chem., 2010, 49, 11276.

19 S. R. Meech and D. Phillips, J. Photochem., 1983, 23, 193.

20 K. Nakamaru, Bull. Chem. Soc. Jpn., 1982, 55, 2697.

21 (a) S. J. Farley, D. L. Rochester, A. L. Thompson, J. A. K. Howard and J. A. G. Williams, Inorg. Chem., 2005, 44, 9690; (b) D. L. Rochester, S. Develay, S. Záliš and J. A. G. Williams, Dalton Trans., 2009, 1728.

22 M. J. Frisch, G. W. Trucks, H. B. Schlegel, G. E. Scuseria, M. A. Robb, J. R. Cheeseman, G. Scalmani, V. Barone, B. Mennucci, G. A. Petersson, H. Nakatsuji, M. Caricato, X. Li, H. P. Hratchian, A. F. Izmaylov, J. Bloino, G. Zheng, J. L. Sonnenberg, M. Hada, M. Ehara, K. Toyota, R. Fukuda, J. Hasegawa, M. Ishida, T. Nakajima, Y. Honda, O. Kitao, H. Nakai, T. Vreven, J. A. Montgomery, Jr, J. E. Peralta, F. Ogliaro, M. Bearpark, J. J. Heyd,
E. Brothers, K. N. Kudin, V. N. Staroverov, R. Kobayashi, J. Normand, K. Raghavachari, A. Rendell, J. C. Burant, S. S. Iyengar, J. Tomasi, M. Cossi, N. Rega, J. M. Millam, M. Klene, J. E. Knox, J. B. Cross, V. Bakken, C. Adamo, J. Jaramillo, R. Gomperts, R. E. Stratmann, O. Yazyev, A. J. Austin, R. Cammi, C. Pomelli, J. W. Ochterski, R. L. Martin, K. Morokuma, V. G. Zakrzewski, G. A. Voth, P. Salvador, J. J. Dannenberg, S. Dapprich, A. D. Daniels, Ö. Farkas, J. B. Foresman, J. V. Ortiz, J. Cioslowski and D. J. Fox, Gaussian 09, 2009.

23 (a) P. Perdew, K. Burke and M. Ernzerhof, Phys. Rev. Lett., 1996, 77, 3865; (b) J. Preat, C. Michaux, A. Lewalle, E. A. Perpète and D. Jacquemin, Chem. Phys. Lett., 2008, 451, 37.

24 B. Yin, F. Niemeyer, J. A. G. Williams, J. Jiang, A. Boucekkine, L. Toupet, H. Le Bozec and V. Guerchais, Inorg. Chem., 2006, 45, 8584.

25 J. Saltiel, G.-E. Khalil and K. Schanze, Chem. Phys. Lett., 1980, 70, 233.

26 For example: A. Bourdrolle, M. Allali, A. D'Aléo, P. L. Baldeck, K. Kamada, J. A. G. Williams, H. Le Bozec, C. Andraud and O. Maury, ChemPhysChem, 2013, 14, 3361. 